\title{
Management of Incidental Finding of Triorchidism Diagnosed During Routine Hernia Repair
}

This article was published in the following Dove Press journal:

Research and Reports in Urology

\author{
Krzysztof Balawender (D) ${ }^{1,2}$ \\ Tomasz Wiatr ${ }^{3}$ \\ Agata Wawrzyniak (iD ${ }^{2}$ \\ Stanisław Orkisz ${ }^{2}$ \\ 'Department of Urology and Urological \\ Oncology, Municipal Hospital in Rzeszow, \\ Rzeszow, Poland; ${ }^{2}$ Morphological \\ Sciences Department of Human \\ Anatomy, Institute of Medical Sciences, \\ Medical College of Rzeszow University, \\ Rzeszow, Poland; ${ }^{3}$ Jagiellonian University \\ Medical College, Department of Urology, \\ Cracow, Poland
}

\begin{abstract}
Polyorchidism is a rare congenital anomaly which refers to the presence of more than two intra- or extrascrotal testicles. Triorchidism, the presence of one extra testicle is the most common type. This report describes the case of a 29 -year-old male who was found to have a right supernumerary undescended testis encountered incidentally during hernia repair. With this in mind, the current knowledge of management of supernumerary testis was analysed, including potential scenarios, to delineate what a urologist should do when a supernumerary testis is found during routine surgical procedures such as orchidopexy or hernia repair.
\end{abstract}

Keywords: triorchidism, polyorchidism, supernumerary testis, orchidectomy, orchidopexy

\section{Introduction}

Triorchidism is an extremely rare congenital anomaly of the genitourinary tract in which one additional testicle is present. Triorchidism is the most frequently encountered form of polyorchidism, which is defined as the presence of more than two intra- or extrascrotal testicles. First histological description of polyorchidism was given in 1880. About 200 cases have been reported in literature, most commonly diagnosed in the paediatric age group, but only 140 were confirmed histologically. ${ }^{1,2}$ The median age of presentation in $50 \%$ of the reported cases was $15-25$ years, with the left side having predominance $(65 \%)$ over the right. ${ }^{3,4}$ The majority of cases presented had either a scrotal or inguinal mass but were otherwise clinically asymptomatic and triorchidism was detected incidentally. ${ }^{3}$

The case presented here is of an adult male patient with a supernumerary undescended testis, confirmed histologically, which was diagnosed incidentally during a routine hernioplasty procedure. This work has been reported in line with the CARE (for CAse REports) criteria. ${ }^{5}$ This case adds to the available data concerning rare congenital abnormalities of testes and in this text, we also consolidate the data published on the topic thus far.

\section{Case Presentation}

A 29-year-old male presented with a reducible swelling in the right inguinal region, with no associated history of trauma or pain. On clinical examination, a reducible swelling in the right inguinal region with a positive cough impulse and positive deep ring occlusion test was noted. Both testes were palpable and normal in size. The vas deferens on both sides was distinct and palpably normal. Sensation over both testes was normal, and there was no significant inguinal lymphadenopathy. The patient subsequently underwent a right inguinal hernioplasty. Intraoperatively, a right indirect inguinal hernia sac was found, containing a small undescended supernumerary testis of size $1.0 \times 1.5 \times 1 \mathrm{~cm}$ at the deep
Correspondence: Krzysztof Balawender Department of Urology and Urological Oncology, Municipal Hospital in Rzeszow, Rycerska 4, Rzeszow, 35-24I, Poland Email balawender82@gmail.com
Research and Reports in Urology 2021:13 |27-|3| 


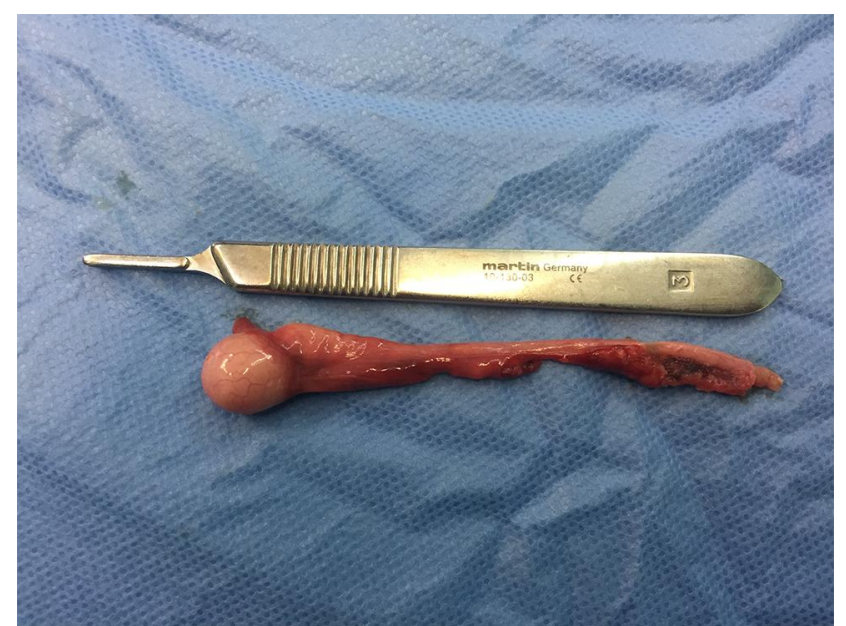

Figure I Intraoperative photograph showing resected supernumerary testis.

inguinal ring (Figure 1). A normally located right testis with palpable epididymis and vas deferens was confirmed within the scrotal sac. Orchidopexy of the supernumerary testis in this case was not possible to perform as the length of the seminal cord did not allow for the free descent of the testis into the scrotum. In addition, there was no structure corresponding to the vas deferens visible macroscopically within the seminal cord. Owing to the abnormal anatomy of supernumerary inguinal testis, orchidectomy with excision of indirect sac was performed. The normally located right testis was preserved within the scrotal sac. The excised testis was referred for histopathological analysis (Figure 2A-D). The testicular tissue was found to be a B1 type variant according to the Bergholz classification (Figure 3). The patient recovered uneventfully.

\section{Discussion}

Triorchidism is the most common form of polyorchidism and may present with a painless scrotal mass, inguinal mass or an undescended testis. A supernumerary testicle may be located in the scrotum $(66 \%)$, inguinal canal $(23 \%)$ or abdomen $(9 \%){ }^{6}$ The majority of patients are asymptomatic and the diagnosis is usually incidental. Anomalies associated with polyorchidism include testicular maldescent (40\%), inguinal hernia (30\%), testicular torsion $(9 \%)$, hydrocele $(9 \%)$, varicocele $(1 \%){ }^{7}$ Extrascrotal supernumerary testes have an increased risk of malignancy. The estimated risk of testicular cancer in polyorchidism is about $5.7 \%$, which is 142 -fold

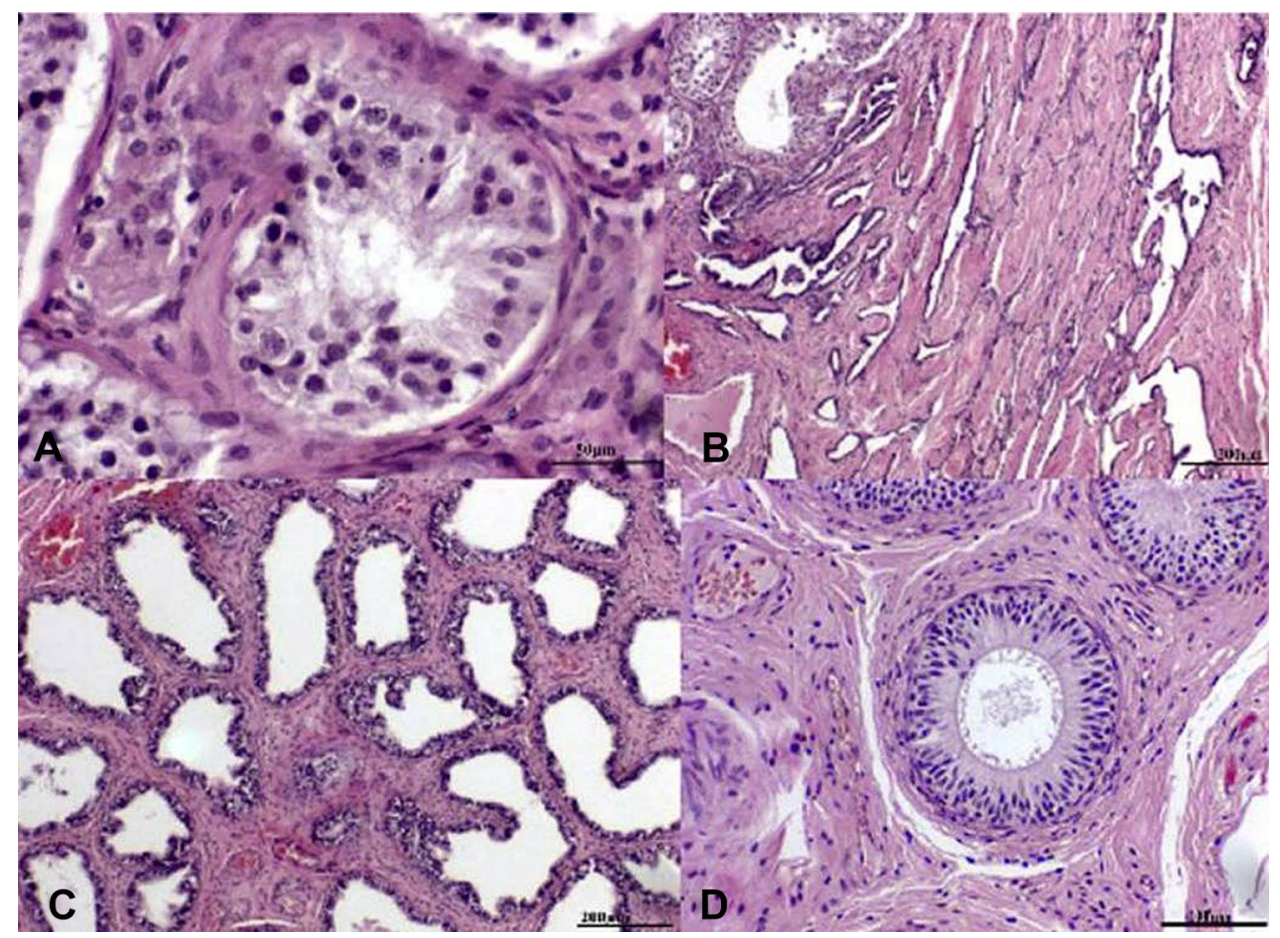

Figure 2 Paraffin sections of seminiferous tubules (A), rete testis (B), efferent ductules (C) and epididymis (D) of supernumerary testis, H\&E staining. The correct structure of the seminiferous tubule with the most characteristic generation of primary spermatocytes has been preserved. Seminiferous tubules surrounded by connective tissue containing Leydig cells (A), scale bar: $50 \mu \mathrm{m}$. In the rete testis is visible a delicate network of channels, lined by a single layer of cuboidal epithelial cells (B), scale bar: $200 \mu \mathrm{m}$. The efferent ductules are lined by a simple epithelium with a characteristic appearance in section, consisting of cuboidal and taller cells (C), scale bar: $200 \mu \mathrm{m}$. The duct of epididymis is lined by a pseudostratified columnar epithelium, surrounded by a thin circular layer of smooth muscle cells. In the lumen is seen to contain semen (D), scale bar: $100 \mu \mathrm{m}$. The samples were analyzed morphologically and photographed under an Olympus BX43 light microscope equipped with an Olympus SC50 digital camera. 


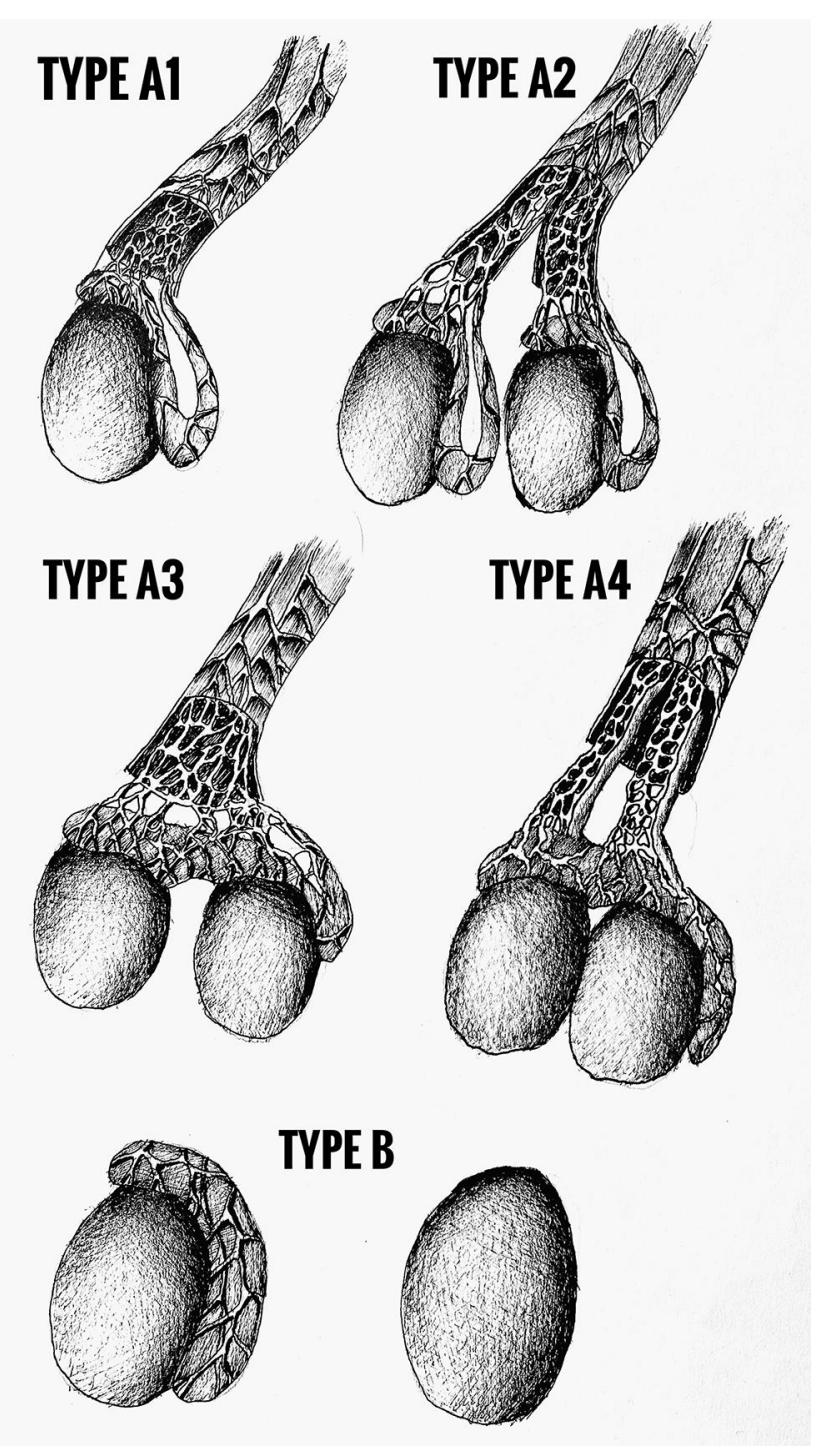

Figure 3 The Bergholz classification of polyorchidism. Images courtesy from and were drawn by Tomasz Wiatr.

higher than the general population and 25-fold higher compared with undescended but not supernumerary testes $(0.004 \%$ for the general population vs. $0.045 \%$ for undescended testes vs. $5.7 \%$ for supernumerary testes). ${ }^{3,8}$ The most common histological types of supernumerary testicular cancer are seminoma, teratoma and choriocarcinoma. ${ }^{2}$

The aetiology of polyorchidism is unclear. One of the possible theories proposed is of accidental division of the genital ridge before 8 weeks gestation. At about 6 weeks of embryonic life, the primordial testis develops from the primitive genital ridge medial to the mesonephric ducts. At about 8 weeks, the primordial testis changes shape and the epididymis and vas deferens rise up from the Wolffian duct. ${ }^{9}$ Other theories propose duplication of the longitudinal genital ridge resulting in separate testis, or transverse division of the genital ridge resulting in a different combination of testis, epididymis and vas deferens. ${ }^{1,10}$

There are a few methods of classification of polyorchidism. The first anatomical classification was proposed by Leung, who classified polyorchidism based on the embryological development with possible anatomically distinct epididymis and vas deferens. ${ }^{1}$ Bergholz et al proposed classification based on the anatomy and reproductive potential of the supernumerary testis (Figure 3). Type A is drained by outflow path (vas deferens): A1- with own epididymis and vas deferens, A2- with own epididymis but common vas deferens with neighbouring testis, A3- common epididymis and vas deferens with neighbouring testis. Type B is not drained by outflow path (B1- with its own epididymis, B2- with no epididymis, thus testicular tissue only). ${ }^{11}$ This case was classified as a B1 type variant according to the Bergholz classification.

Management of triorchidism has evolved over time but remains debatable. As polyorchidism is an extremely rare congenital abnormality, there are few cases to facilitate evidence-based recommendations. Traditional management involves surgical removal of the supernumerary testis due to increased malignancy risk, but recent reports have recommended conservative management in some cases. Histological examination of surgically explored cases revealed a functional parenchyma in $50-65 \%$ of the supernumerary testes. ${ }^{12}$ Thus, patients with a scrotal supernumerary testis with no radiological concerns of malignancy may be recommended conservative management and monitoring, with regular clinical examination and non-invasive imaging (ultrasound or magnetic resonance imaging). In polyorchidism with an extrascrotal testis, especially in a young patient of reproductive age, orchidopexy is recommended if feasible, followed by observation. If a supernumerary testis is associated with any signs of malignancy, radical orchidectomy is recommended. In our study, we propose a therapeutic algorithm based on current knowledge that can be used in everyday clinical practice (Figure 4). 


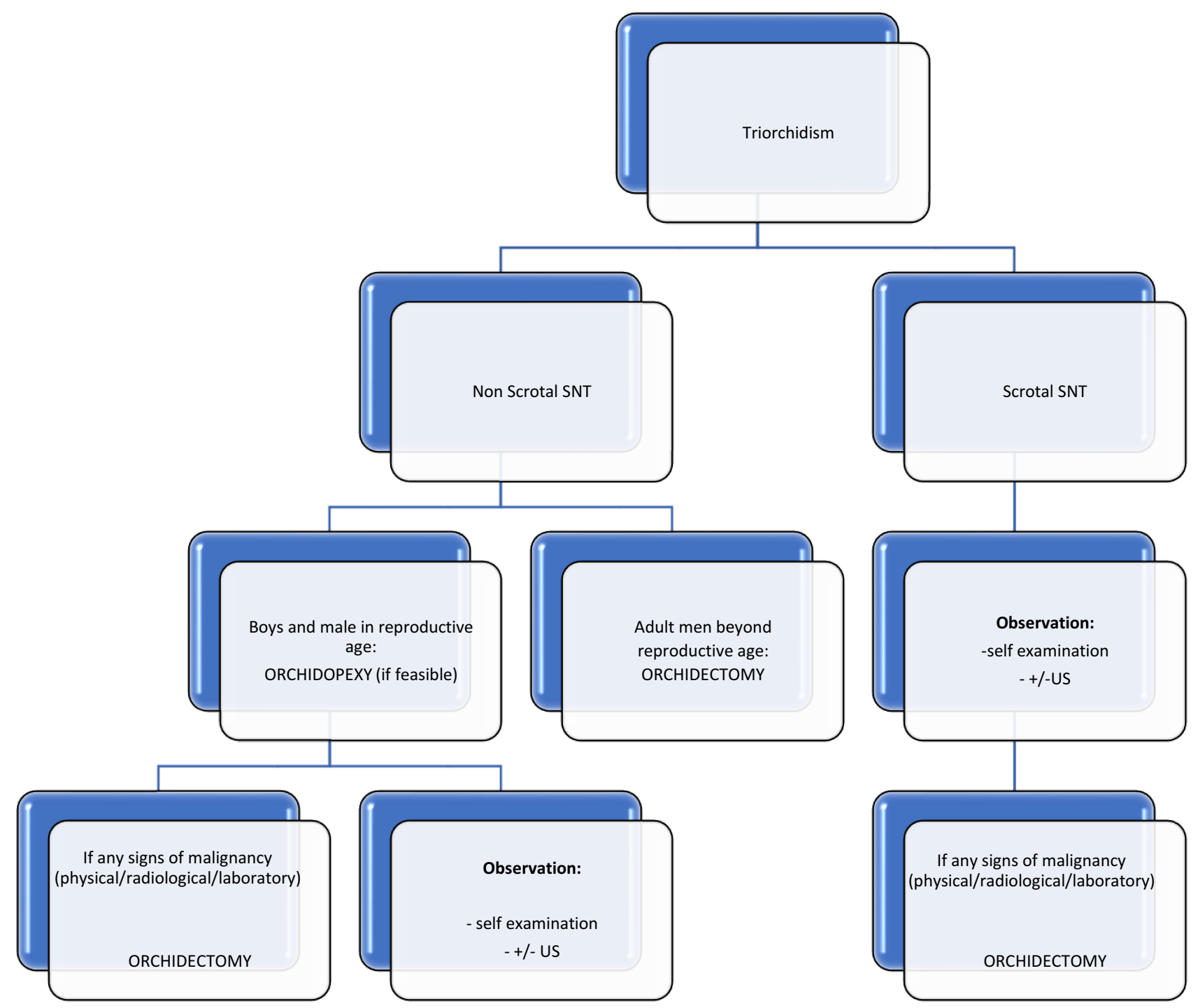

Figure 4 Therapeutic algorithm for triorchidism.

Abbreviations: SNT, supernumerary testis; US, ultrasonography.

\section{Conclusion}

Triorchidism is a rare congenital abnormality usually diagnosed incidentally, and its management is still controversial. Based on the analysis of available reports, conservative management should be recommended for scrotal triorchidism, and surgical orchidopexy with preservation of the supernumerary testis should be recommended for extrascrotal triorchidism, particularly in patients of reproductive age.

\section{Abbreviations}

SNT, supernumerary testis; US, ultrasonography.

\section{Ethics Approval and Informed Consent}

Written informed consent has been provided by the patient to have the case details and any accompanying images published. Institutional approval was not required to publish the case details.

\section{Author Contributions}

All authors made substantial contributions to conception and design, acquisition of data, or analysis and interpretation of data; took part in drafting the article or revising it critically for important intellectual content; agreed to submit to the current journal; gave final approval of the 
version to be published; and agree to be accountable for all aspects of the work.

\section{Disclosure}

The authors report no conflicts of interest in this work.

\section{References}

1. Pettersson A, Richiardi L, Nordenskjold A, Kaijser M, Akre O. Age at surgery for undescended testis and risk of testicular cancer. $N$ Engl $J$ Med. 2007;356(18):1835-1841. doi:10.1056/NEJMoa067588

2. Sonmez NC, Kılınç F, Arısan S, Calıskan KC. Polyorchidism: a case report and review of the literature. Andrology. 2012;1:102. doi:10.4172/2167-0250.1000102

3. Abduljabbar AH. A case report: triorchidism; is a rare mistaken cause for extra testicular neoplasm. Urol Case Rep. 2015;3(3):89-91. doi:10.1016/j.eucr.2015.02.002

4. Kundu AK, Deb D, Pradhan P, Ghosh G, Chakrabarty S. Triorchidism: an incidental finding and review of literature. $J$ Anat Soc India. 2001;50:37-39. doi:10.4103/2006-8808.110262
5. Riley DS, Barber MS, Kienle GS, et al. CARE guidelines for case reports: explanation and elaboration document. J Clin Epidemiol. 2017;89:218-235. doi:10.1016/j.jclinepi.2017.04.026

6. Kheirandish P, Chinegwundoh F. An unusual case of triorchidism. JRSM Short Rep. 2010;1(6):1-3. doi:10.1258/shorts.2010.010067

7. Kharrazi SMH, Rahmani MR, Sakipour M, Khoob S. Polyorchidism: a case report and review of literature. Urol J. 2006;3(3):180-182. doi:10.1186/1752-1947-8-464

8. Bergholz R, Wenke K. Polyorchidism: a meta-analysis. J Urol. 2009;182(5):2422-2427. doi:10.1016/j.juro.2009.07.063

9. Hassan A, El-Mogy S, Mostafa T. Triorchidism: a case report and review of similar conditions. Andrologia. 2008;40(4):265-269. doi:10.1111/j.1439-0272.2008.00843.x

10. Haddock G, Burns HJ. Polyorchidism. Postgrad Med J. 1987;63 (742):703-705. doi:10.1136/pgmj.63.742.703

11. Bergholz R, Koch B, Spieker T, Lohse K. Polyorchidism: a case report and classification. J Pediatr Surg. 2007;42(11):1933-1935. doi:10.1016/j.jpedsurg.2007.07.031

12. Spranger R, Gunst M, Kühn M. Polyorchidism: a strange anomaly with unsuspected properties. $J$ Urol. 2002;168(1):198. doi:10.1016/ s0022-5347(05)64868-9

\section{Publish your work in this journal}

Research and Reports in Urology is an international, peer-reviewed, open access journal publishing original research, reports, editorials, reviews and commentaries on all aspects of adult and pediatric urology in the clinic and laboratory including the following topics: Pathology, pathophysiology of urological disease; Investigation and treatment of urological disease; Pharmacology of drugs used for the treatment of urological disease. The manuscript management system is completely online and includes a very quick and fair peer-review system, which is all easy to use. Visit http://www.dovepress.com/ testimonials.php to read real quotes from published authors. 